\title{
Online learning during the Covid-19 pandemic: the experiences and perceptions of undergraduate occupational therapy students at two Australian universities
}

\section{Online Lernen während der Covid-19 Pandemie: Erfahrungen und Wahrnehmungen von Bachelor Studierenden der Ergotherapie an zwei australischen Universitäten}

Ted Brown ${ }^{1 *}$, Luke Robinson', Kate Gledhill', Annette Peart',

Mong-Lin Yu' ', Stephen Isbel' ${ }^{2}$, Craig Greber ${ }^{2}$, Jamie Etherington'

\author{
${ }^{1}$ Department of Occupational Therapy, School of Primary \\ and Allied Health Care, Faculty of Medicine, Nursing and \\ Health Sciences, Monash University, Peninsula Campus, \\ Frankston, Victoria, Australia \\ ${ }^{2}$ Occupational Therapy Program, Faculty of Health, The \\ University of Canberra Hospital, Bruce, Australian Capital \\ Territory, Australia \\ *ted.brown@monash.edu
}

Received 12 April 2021, accepted 10 June 2021

\begin{abstract}
Purpose: To investigate if first-year occupational therapy students who have had no on-campus, face-to-face learning experiences differed from second-, third- and fourth-year students in their perceptions and experiences of online learning during the Covid-19 pandemic.

Methods: One hundred and fifty-one occupational therapy undergraduate students (80.8\% female; $66.2 \% 20-24$ old) completed the Student Engagement in the e-Learning Environment Scale (SELES) and the Distance Education Learning Environment Scale (DELES). Analysis of variance (ANOVA) with bootstrapping was completed to examine the differences between first-year and senior students' perceptions and experiences of online learning.

Results: Significant differences were observed across several SELES and DELES scales: peer collaboration (SELES) $(p=.001)$, interactions with instructors (SELES) $(p=.026)$, student interaction and collaboration (DELES) $(p=.003)$, authentic learning (DELES) $(p=.026)$ and active learning (DELES) $(p=.013)$

Conclusion: The findings demonstrate significant differences in first-year and senior students' perceptions and experiences of online learning during the Covid-19 pandemic. The outcomes highlight the importance of facilitating collaborative and active engagement for all students by implementing academic, technological and social support measures within occupational therapy curricula.
\end{abstract}

\begin{abstract}
Ziel der Studie: Untersuchung ob sich die Erfahrungen und Wahrnehmungen mit/von 'online learning' während der Covid-19 Pandemie der Ergotherapie-Studenten in ihrem ersten Lehrjahr, die keine Campusveranstaltungen oder Präsenzveranstaltungen besucht haben, von den Erfahrungen und Wahrnehmungen der Studenten im zweiten, dritten oder vierten Lehrjahr unterscheiden.

Methoden: 151 Ergotherapie Bachelor Studenten (80.8\% weiblich; 66.2\% 20-24 Jahre) haben das 'Student Engagement in the e-Learning Environment Scale' (SELES) und das 'Distance Education Learning Environment Scale' (DELES) abgeschlossen. Eine Varianzanalyse (ANOVA) mit Bootstrapping wurde zur Auswertung der Unterschiede zwischen den Erfahrungen und Wahrnehmungen mit/von 'online learning' der Studenten im ersten Lehrjahr und der Studenten höherer Semester durchgeführt.

Resultat: Zwischen den SELES und DELES Auswertungen konnten signifikante Unterschiede festgestellt werden: kollegiale Zusammenarbeit (Peer Collaboration) (SELES) ( $p=.001$ ), Interaktionen mit Dozent:innen (Interactions with Instructors) (SELES) ( $p=.026)$, Interaktion und Zusammenarbeit unter Studenten (Student Interaction and Collaboration) (DELES) $(p=.003$ ), authentisches Lernen (Authentic Learning) (DELES) $(p=.026)$ and aktives Lernen (Active Learning) (DELES) $(p=.013)$.

Fazit: Die Ergebnisse zeigen signifikante Unterschiede in den Erfahrungen und Wahrnehmungen mit/von digitalem Lernen während der Covid-19 Pandemie zwischen Ergotherapie Studenten im 'online learning' und Studenten höherer Semester. Die Resultate zeigen die Relevanz der Förderung des kollaborativen und aktiven Engagements für alle Studenten durch die Implementierung von akademischen, technologischen und sozial-fördernden Maßnahmen im Fachbereich der Ergotherapie.
\end{abstract}

\section{Keywords}

Occupational therapy students - Covid-19 - education - face-to-face learning - remote learning - telehealth

\section{Keywords}

Ergotherapie Studenten - Covid-19 - Bildung - Präsenzunterricht - Fernunterricht 


\section{INTRODUCTION}

The coronavirus disease 2019 (Covid-19) pandemic has changed many aspects of the way we live, learn and work, and the full impact of lockdowns, social distancing and isolation at individual and societal levels are only now beginning to emerge (Nicola et al., 2020; O'Sullivan et al., 2020). The ongoing crisis is a reminder for those in the higher education sector that students' education and academic behaviours are embedded in wider political, cultural and social systems (Burki, 2020; Thatcher et al., 2020). For academic and clinical educators in health professions training, the pandemic has created significant obstacles regarding the delivery of pre-qualification education of students, as institutions and academics adjusted teaching programmes at short notice in the face of rapidly imposed restrictions on social gatherings (Coto et al., 2020; Rabe et al., 2020; Robinson et al., 2020). Traditionally, changes to the delivery of curricula have taken years to research, implement and evaluate, yet the current crisis has forced academics to make radical changes in a short period of time (Scott, 2020).

This is the first time that many health profession education programmes at the entry-to-practice degree level have been delivered entirely online. Globally, medical, nursing and allied health professional education faculty will seek to learn from students' experiences and implement appropriate support measures that facilitate their full engagement in remote learning. While the difficulties presented have been unique, the challenges present invaluable learning opportunities for the design of future health education curricula (Gustaffson, 2020). This is what Marks (2020) refers to as 'the unexpected silver lining' to the current crisis: the once-in-a-lifetime opportunity to explore the impact and effectiveness of delivering programmes, including theoretical knowledge and the learning of practical skills, to health professional students entirely via online platforms.

Over the last decade, blended or hybrid learning, in which content is delivered both face-to-face and remotely, has been the preferred approach of education providers across most disciplines (Cuesta Medina, 2018; Liu et al., 2016). This is particularly the case in the health professions, which have actively promoted the integration of online and traditional face-to-face learning experiences within undergraduate curricula. Studies report the benefits of hybrid educational models in providing opportunities for content to be delivered in innovative and flexible ways such as online video lectures, web conferencing and discussion forums that do not endanger positive performance outcomes (Jensen \& Lally, 2018; McCutcheon et al., 2015; Mu et al., 2014; Scagnoli et al., 2019). Further, case studies comparing traditional face-to-face classroom instruction to programmes where technology is used to deliver content in both general higher education settings and health professional education contexts have found no discernible differences in the effectiveness of students' learning (Allen \& Seaman, 2013; Mu et al., 2014; Means et al., 2009; Rogers et al., 2011). In contrast, findings from the medical, nursing and allied health sectors suggest that education programmes weighted in favour of online learning with minimal face-to-face contact time can negatively affect students (Regmi \& Jones, 2020). These include feelings of social isolation, difficulties forging supportive peer and professional relationships, and inability to develop effective communication skills and full empathic rapport with peers, patients, and their families, and educators (Bezerra, 2020; Longhurst et al., 2020; Rogers et al., 2011).

In the context of Covid-19, the switch from face-to-face instruction to modules delivered via digital platforms such as Zoom and Microsoft Teams has been challenging for all students (Marks, 2020). The effects are reported to have been most acutely noted in disciplines with components of hands-on learning such as the health sciences, engineering and the performing arts, where students felt that online learning did not represent value for money in relation to tuition fees paid (Zhou, 2020). During the current extended period of online learning, many students have experienced time management issues, which has resulted in them feeling unmotivated and anxious as well as professionally and socially isolated (Gustaffson, 2020).

An early survey of undergraduates enrolled in universities in Western Australia reported between 33\% and $50 \%$ of students were unhappy with online learning, citing difficulties engaging with content and educators, dissatisfaction with the lack of face-to-face classroom learning, feeling isolated from their peers, ongoing technological issues and concerns over the negative impact on examinations and assessments (Zhou, 2020). A further theme that emerged was the lack of access to university libraries which, prior to the onset of the pandemic, represented spaces conducive to quiet study and social interactions with peers. One positive aspect of remote learning reported by a minority of students, however, was an appreciation of flexible access to educational resources provided by online instruction (Zhou, 2020). These challenges and experiences may have different impacts on the first-year students who are new to university compared to second-, third- and fourthyear students.

The challenge for educators is to facilitate flexible access to online learning in ways that provide all students with meaningful experiences and promote full engagement in active and genuine learning, whilst safeguarding their social and personal well-being. This study investigates the experiences and perceptions of online learning over 
the mandated Covid-19 lockdown period in a cohort of first- to fourth-year students enrolled in two occupational therapy programmes at two Australian universities. The findings will inform the future integration, organisation and delivery of traditional and new forms of teaching and learning experiences in occupational therapy curricula and will assist the development of academic, technological and social support initiatives. This study will also contribute to the body of evidence-based education in the health professional disciplines.

\section{METHODS}

\section{Participants}

Occupational therapy students who were enrolled in the 4-year Bachelor of Occupational Therapy (Honours) programme at Monash University (445 students) and in the 4-year Bachelor of Occupational Therapy (Honours)/ Bachelor of Occupational Therapy at the University of Canberra (100 students), Australia, were invited to take part in the study. Students enrolled in the first year of the occupational therapy programmes were labelled as 'firstyear' students, whereas students enrolled in second, third and fourth year of the occupational therapy programmes were identified as 'senior' students in the context of this study.

Students were alerted to the research study via a learning management system (LMS) announcement that included an overview of the project and participant information statement. In total, 182 responses were received, but 31 participants' responses were removed prior to data analysis due to incomplete information reported or missing data. This resulted in a sample size of 151 participants and response rates for the two courses of $31 \%$ and $13 \%$, respectively. Students were provided with a weblink to a Qualtrics link where they could complete the online questionnaire that comprised three sections: a demographic questionnaire, the Student Engagement in the e-Learning Environment Scale (SELES) (Lee et al., 2019) and the Distance Education Learning Environment Scale (DELES) (Walker \& Fraser, 2005).

To be able to enrol at Monash University or the University of Canberra, students were required to have the necessary technology setup for them to be able to engage with their universities' learning management system at a distance. This included having the necessary hardware, software and connectivity level. When students at Monash University or the University of Canberra moved to online learning over the mandated Covid-19 lockdown period during 2020, both universities provided limited one time only financial aid grant payment that students could apply for to assist with funding the technology costs of moving to online remote learning. Students had to meet specific eligibility criteria and provide evidence of financial need to access the funding scheme. Both universities also provided technology support service hubs that students can access online or via phone during business hours each day if they experienced difficulties. Standard software programmes are provided to students when they enrol at each university as one of the resources they can access after they pay their tuition fees.

The education delivery context for both occupational therapy courses offered at Monash University or the University of Canberra during the mandated Covid-19 lockdown period during 2020 included a combination of pre-recorded content lectures that students could access at any time during their independent study time, live online weekly facilitated tutorial sessions that students were expected to attend delivered via online platforms (e.g., Zoom or Microsoft Teams) that were not recorded, and live online practical skills sessions that students were expected to attend that were delivered via online platforms (that were not recorded). Moodle, an open-source course management system, was used as the unit delivery system where students could access the pre-recorded lectures, access lecture notes, retrieve prescribed readings, view other related learning materials and upload assignments. Weekly scheduled drop-in sessions via the online platforms (e.g., Moodle) where students could log on and speak with academic staff, online forums via the Moodle sites where students could post questions, and individual appointments time slots where students could book in a meeting with an educator were all available for students.

\section{Instrumentation}

The data were generated in three parts. The first part gathered descriptive demographic data via an online self-report questionnaire, in which students reported the university of enrolment, their year level, enrolment status, age, gender, whether English is their first spoken and written language, and international or domestic student status. The second and third parts of the questionnaire consisted of the SELES (Lee et al., 2019) and DELES (Walker \& Fraser, 2005), standardised self-report instruments to generate information about students' engagement with and experiences of online e-learning. The SELES tool was specifically designed to assist instructors and curriculum developers in improving conditions that promote students' engagement in e-learning environments and reduce the risk of students dropping out of online courses (Lee et al., 2019). The instrument consists of 24 statements, of which participants rate their opinion on a Likert scale (1 = Never; 5 = Always). Responses load to six subscales: psychological motivation, peer collaboration, cognitive problem solving, interaction with instructors, community 
support and learning management (Lee et al., 2019). The score range for each of the six SELES subscales is 1-5 and is determined by calculating the mean rating score received for each subscale. A mean rating score of $>4.0$ is considered high, a rating $>2.5$ and $<3.99$ is moderate, and a mean rating of $<2.5$ is low. Therefore, a high mean rating score on one of the SELES subscales would represent a high level of endorsement of that subscale and a low mean rating score would represent a low level of endorsement. The SELES has high levels of proven validity and reliability with Cronbach's alpha coefficients ranging from 0.72 (learning management scale) to 0.90 (psychological motivation scale), where 0.70 or above is considered adequate (Lee et al., 2019). Validity evidence of the SELES was established through exploratory and confirmatory factor analysis results (Lee et al., 2019).

The DELES instrument was developed to help educators and researchers gauge students' perceptions of distance learning environments and highlight areas that can be improved to enhance learning outcomes (Walker, 2020). It is used to measure and determine the extent of associations between distance education programmes and students' enjoyment of their studies. Students rate the frequency of their engagement with 42 statements using a Likert scale $(1=$ Never; $5=$ Always $)$, and their responses load to seven subscales: instructor support, student interaction and collaboration, personal relevance, authentic learning, active learning, student autonomy and enjoyment (Walker, 2020). The score range for each of the seven DELES subscales is $1-5$ and is determined by calculating the mean frequency of engagement rating score received for each subscale. A mean rating score of $>4.0$ is considered high, a rating $>2.5$ and $<3.99$ is moderate, and a mean rating of $<2.5$ is low. Therefore, a high mean rating score on one of the DELES subscales would represent a high level of engagement in what the subscale factor represented and a low mean rating score would represent a low level of engagement. The instrument has reported excellent internal consistency and Cronbach's alpha coefficients ranging from 0.75 to 0.94 for the six psychosocial subscales and 0.95 for the enjoyment affect scale (Walker, 2020). Evidence of the DELES's validity has also been reported (Walker, 2020).

\section{Data management and analysis}

The Statistical Package for the Social Sciences (SPSS), version 25 (IMB Corporation, 2017), for Windows, was used for data entry, storage and analysis. Descriptive statistics of the demographic information and the SELES and DELES subscales were completed. Analysis of variance (ANOVA) was then carried out to analyse the differences between first-year and senior students in their engagement with and experiences of online learning.
Tests of homogeneity using Levene's statistic to assess the equality of variances were completed where variances are not equal below $p<.05$.

'Bootstrapping', a reliable resampling technique that uses a type of robust statistic to infer a population from sample data, was applied (Chernick, 2007). This method improves the accuracy of the confidence intervals (CIs) by taking, with replacement, the values from the original sample to obtain 1000 bootstrapped samples. Results were considered statistically significant at the .05 alpha level.

\section{Procedures}

Ethics approval for the project was obtained from the Monash University Human Research Ethics Committee (MUHREC) (Project Number: 25624). Students enrolled in the Bachelor of Occupational Therapy (Honours)/ Bachelor of Occupational Therapy programmes at the two universities were informed of the purpose of the study, the voluntary nature of their participation and the procedures to ensure their anonymity in all published outputs. The online questionnaire took approximately 20 minutes to complete, and consent on the part of the students was implied by its completion and online submission. Students' completion of the SELES and DELES instruments was independent of their occupational therapy studies and formal assessment procedures. Respondents were under no obligation to take part in the study and did not receive gratification points, extra grades or credit for participating in the study. No data were identifiable, and anonymity of responses was assured.

\section{RESULTS}

The sample of predominantly 20- to 24-year-old, female, full-time undergraduate occupational therapy students was evenly distributed across the 4 years of the two programmes. The majority were domestic students with English as their primary spoken and written language. The full demographic findings are reported in Table 1.

Across the instruments, first year students recorded their highest score on the DELES instructor support $(\mathrm{M}=4.02$, $\mathrm{SD}=0.53)$ psychosocial scale and senior students scored highest on the DELES student autonomy psychosocial scale $(M=4.10, S D=0.70)$. Both groups returned lowest scores on the DELES enjoyment affective subscale (first year, $\mathrm{M}=2.64, \mathrm{SD}=1.06$; senior, $\mathrm{M}=2.62, \mathrm{SD}=$ 1.07), and they recorded low scores on the SELES peer collaboration (first year, $\mathrm{M}=2.73 ; \mathrm{SD}=0.76$ ) and SELES interactions with instructors (seniors, $\mathrm{M}=2.58$; $\mathrm{SD}=$ 0.88 ) subscales. See Table 2 for the full mean scores. ANOVA calculations revealed key findings in demonstrating significant differences between first- 
Table 1: Demographic data $(n=151)$.

\begin{tabular}{|c|c|c|}
\hline & Frequency & Percentage \\
\hline University & & \\
\hline University of Canberra & 13 & 8.6 \\
\hline Monash University & 138 & 91.4 \\
\hline Year level & & \\
\hline First-year undergraduate & 39 & 25.8 \\
\hline Second-year undergraduate & 35 & 23.2 \\
\hline Third-year undergraduate & 51 & 33.8 \\
\hline Fourth-year undergraduate & 26 & 17.2 \\
\hline Enrolment status & & \\
\hline Full-time & 145 & 96.0 \\
\hline Part-time & 6 & 4.0 \\
\hline Age & & \\
\hline $17-19$ years & 35 & 23.2 \\
\hline $20-24$ years & 100 & 66.2 \\
\hline $25-29$ years & 7 & 4.6 \\
\hline $30-34$ years & 2 & 1.3 \\
\hline $35-39$ years & 6 & 4.0 \\
\hline 40 years or older & 1 & 0.7 \\
\hline \multicolumn{3}{|l|}{ Gender } \\
\hline Female & 122 & 80.8 \\
\hline Male & 28 & 18.5 \\
\hline Prefer not to say & 1 & 0.7 \\
\hline \multicolumn{3}{|l|}{ English as first language } \\
\hline Yes & 112 & 74.2 \\
\hline No & 39 & 25.8 \\
\hline \multicolumn{3}{|l|}{ Student status } \\
\hline International student & 38 & 25.2 \\
\hline Domestic student & 113 & 74.8 \\
\hline
\end{tabular}

Table 2: SELES and DELES comparative mean scores for first-year $(n=$ 39) and senior year ( $n=112$ ) occupational therapy students.

\begin{tabular}{c|c|c|c|c}
\hline & $\begin{array}{c}\text { First-year } \\
\text { students } \\
\text { Mean }\end{array}$ & SD & $\begin{array}{c}\text { Senior } \\
\text { students } \\
\text { Mean }\end{array}$ & SD \\
\hline SELES subscales & & & & \\
\hline Psychological motivation & 3.04 & \pm 0.89 & 2.90 & \pm 0.88 \\
\hline Peer collaboration & 2.73 & \pm 0.76 & 3.24 & \pm 0.88 \\
\hline Cognitive problem solving & 3.22 & \pm 0.74 & 3.36 & \pm 0.70 \\
\hline Interactions with instructors & 2.92 & \pm 0.91 & 2.58 & \pm 0.88 \\
\hline Community support & 2.74 & \pm 0.84 & 2.91 & \pm 0.89 \\
\hline Learning management & 3.39 & \pm 0.70 & 3.25 & \pm 0.80 \\
\hline DELES subscales & & & & \\
\hline Instructor support & 4.02 & \pm 0.53 & 3.90 & \pm 0.75 \\
\hline $\begin{array}{c}\text { Student interaction and } \\
\text { collaboration }\end{array}$ & 3.18 & \pm 0.84 & 3.62 & \pm 0.70 \\
\hline Personal relevance & 3.55 & \pm 0.79 & 3.57 & \pm 0.73 \\
\hline Authentic learning & 3.45 & \pm 0.76 & 3.75 & \pm 0.71 \\
Active learning & 3.58 & \pm 0.64 & 3.88 & \pm 0.63 \\
Student autonomy & 3.88 & \pm 0.62 & 4.10 & \pm 0.70 \\
Enjoyment & 2.64 & \pm 1.06 & 2.62 & \pm 1.07 \\
\hline
\end{tabular}

$S D=$ standard deviation, SELES = Student Engagement in the e-Learning Environment Scale, DELES = Distance Education Learning Environment Scale.
Table 3: Analysis of variance of SELES and DELES subscales ( $n=151$; bootstrapped sample of 1000).

\begin{tabular}{c|c|c|c|c|c}
\hline & $\begin{array}{c}\text { Sum of } \\
\text { squares }\end{array}$ & df & $\begin{array}{c}\text { Mean } \\
\text { square }\end{array}$ & $\mathbf{F}$ & $\boldsymbol{p}$-value \\
\hline SELES subscales & & & & & \\
\hline $\begin{array}{c}\text { Psychological } \\
\text { motivation }\end{array}$ & .544 & 1 & .544 & .700 & .404 \\
\hline $\begin{array}{c}\text { Peer collaboration } \\
\text { Cognitive problem } \\
\text { solving }\end{array}$ & 7.768 & 1 & 7.768 & 10.761 & .001 \\
\hline $\begin{array}{c}\text { Interactions with } \\
\text { instructors }\end{array}$ & 3.987 & 1 & 3.987 & 5.061 & .026 \\
\hline Community support & 1.094 & 1 & 1.094 & 1.406 & .238 \\
\hline Learning management & .560 & 1 & .560 & .923 & .338 \\
\hline DELES subscales & & & & & .288 \\
\hline Instructor support & .555 & 1 & .555 & 1.135 & .288 \\
\hline $\begin{array}{c}\text { Student interaction and } \\
\text { collaboration }\end{array}$ & 4.846 & 1 & 4.846 & 8.897 & .003 \\
\hline Personal relevance & .011 & 1 & .011 & .020 & .888 \\
\hline Authentic learning & 2.640 & 1 & 2.640 & 5.060 & .026 \\
\hline Active learning & 2.458 & 1 & 2.458 & 6.272 & .013 \\
\hline Student autonomy & 1.370 & 1 & 1.370 & 2.972 & .087 \\
\hline Enjoyment & .018 & 1 & .018 & .016 & .900 \\
\hline
\end{tabular}

SELES = Student Engagement in the e-Learning Environment Scale; $D E L E S=$ Distance Education Learning Environment Scale.

year and senior students in their experiences of, and engagement with, online learning; these are reported in Table 3. See Table 3 for full ANOVA results.

\section{Peer collaboration and student interactions}

Applying analysis of variance to determine the ratio of between group variation, statistically significant differences were observed between first-year and senior students on measures of peer collaboration (SELES) $[\mathrm{F}(1,147)=10.761, p=.001$, based on 1000 bootstrap samples] and student interaction and collaboration $($ DELES $)[F(1,147)=8.897, p=.003$, based on 1000 bootstrap samples]. Levene's test of homogeneity showed that the variances between first-year and senior students based on mean and median scores were not equal. Firstyear students reported significantly lower rates of peer collaboration (SELES) $(p=.001)$ and student interaction and collaboration (DELES) compared to their senior student peers enrolled in second, third and fourth years of study $(p=.003)$.

\section{Authentic and active learning}

Significant lower scores were found in first-year students compared to senior students on measures of authentic learning (DELES) $([\mathrm{F}(1,147)=5.060, p=.026$, based on 1000 bootstrap samples] and active learning (DELES) $[F(1,147)=6.272, p=.013$, based on 1000 bootstrap 
samples]. Levene's statistic identified that the variances between first-year and senior students based on mean and median scores were not equal. In other words, selfreported levels of active learning $(p=.013)$ were noted to be significantly higher in senior student peers enrolled in second, third and fourth years of study. Likewise, the senior student cohort also appeared to experience higher levels of authenticity and positivity $(p=.026)$ in their university studies compared to first-year student group.

\section{Interactions with educators}

A further key finding was determining a statistically significant higher interactions with instructors (SELES) subscale score in first-year students than in senior students $[\mathrm{F}(1,147)=5.061, p=.026$, based on 1000 bootstrap samples]. The test of homogeneity determined that the variance between first-year and senior students based on mean and median scores was not equal.

\section{DISCUSSION}

This study explored the experiences and perceptions of online learning during Covid-19 in two groups of occupational therapy students: first-year students who had received no prior on-campus, face-to-face education in higher education context; and senior students with prior experience of on-site learning. From March 2020 onwards during the academic year in Australia, students enrolled in the two occupational therapy programmes were required to attend tutorials and practical skills sessions, complete presentations, and submit written assignments and assessments via online. The practice education of the majority of senior year students in their third and fourth years of study was severely impacted as many of them were unable to undertake (or have reduced proportion of) in-person fieldwork placements at clinical sites. Instead, these were largely replaced with simulation exercises and telehealth placements (Robinson et al., 2020).

The mean scores across the two instruments reveal that all students, irrespective of year level, were challenged during the extended period of online learning. The low scores recorded on measures of psychological motivation, community support and enjoyment suggest the experiences of both sets of students were characterised by poor motivation, lack of stimulation, isolation and missing the peer and social supports that are a central part of life on-campus. It is encouraging to note, however, the scores recorded by first-year and senior students on measures of student autonomy and learning management, which indicate students were adept at taking positive and active control of their learning, making decisions about their learning and determining when they would study. While students may not have enjoyed the extended period of remote learning, the online learning process may have strengthened students' autonomous learning capabilities. Analysis of the SELES and DELES scores, which measure students' engagement in the e-learning process and explore the psychosocial factors of distance education, produced three key findings: (i) students in the second to fourth years of study reported significantly higher rates of peer collaboration $(p=.001)$ and peer interaction $(p=.003)$; (ii) self-reported levels of active learning ( $p=.013$ ) were observed to be significantly stronger in senior students who also experienced higher levels of authenticity and positivity $(p=.026)$ in their learning, compared to first-year students; and (iii) firstyear students' communications and interaction with instructors were significantly more frequent than senior year students $(p=.026)$. It is important to add the caveat that both student groups recorded low scores on this subscale.

\section{Peer collaboration and student interactions}

Analysis of variance procedures established significant differences in first-year and senior year students' experiences of collaborative peer learning. These typically involve activities in which learners discuss knowledge and collaboratively solve problems, a process which positively engages students to facilitate the building and understanding of knowledge and skills. The finding that senior students' experiences of collaborative and interactive learning were significantly different to those of first-year students could be a factor of more experienced older students having already established personal and peer support networks and gained a sense of a community of learning. These are reported as essential elements that facilitate students to develop and share their understandings of the learning context and co-create knowledge (Khalili, 2020). As first-year students in this study had few opportunities to build friendship groups and develop peer learning networks in classroom settings, the low level of peer collaboration and interaction found in the current study is not an unexpected finding.

In the context of a female-dominant cohort, the finding is also contingent with the results of a large-scale global study that investigated the impact of the Covid-19 response on university students, which found that first-year female students in the applied sciences were generally affected more by the pandemic in terms of academic work and life, and their emotional and personal circumstances (Aristovnik et al., 2020). The low levels of engagement and interaction among first-year students also link with earlier studies of online learning among graduates, in which students reported missing the interplay of lived space, time and human relations inherent in face-toface classroom settings, encompassing important social 
elements of spontaneity, immediate feedback and conversations (Keengwe \& Wilsey, 2012).

Difficulties in conducting group work and allocation of tasks are reported to be a common issue with distance learning, highlighting the need for educators to ensure technological and logistical support for students, good channels of communication and the smooth coordination of the creative and pedagogical process for delivery of content online (Rogers et al., 2011). This is particularly relevant for first-year students who are in the early stages of developing academic and social networks and their understandings of programme requirements. In the absence of face-to-face interactions, peer mentoring via online technologies better enable students to sustain motivation, maintain a sense of connection with their university, commit to their academic and professional work, and build communities of support (Jacobs et al., 2013).

In terms of positive learning achievement and the development of desirable core competencies in health professions students (e.g., higher-order thinking), it is important that educators build on evidence of the positive aspects of e-learning approaches to the delivery of content (Chen et al., 2010; Robinson \& Hullinger, 2008). For example, students' active engagement with the online learning process is associated with improvements in work effort, interpersonal actions and the application of critical thinking, problem-solving skills and acquired knowledge to real-world settings, resulting in better academic performance (Carini et al., 2006; Lewis et al., 2011).

Senior students' greater positive experience of interactions and collaboration with peers, compared to first-year students, suggests that the networks formed during the first academic semesters are important for developing attachments and connections that enable collaborative working. Keptner and McCarthy (2020) emphasise that when students feel they are a member of a class or cohort, they often gain a sense of belonging, but these bonds can be hard to achieve when education programmes are delivered using virtual methods. For first-year students during the period of remote learning, being denied opportunities for face-to-face contact and getting to know academic staff, tutors and fellow students in the new intake, the issues are compounded. Stronger affiliative and attachment structures among senior students may therefore facilitate remote collaborative working among peers using a variety of technological tools.

In addition to institution-led videoconferencing tutorials, pre-recorded lectures, online lectures and practical sessions, students also used private tools to communicate and work with each other. The most popular private means of communicating with fellow students during e-learning were reported to include private and team chat messages and two- and multi-participant video 'hook-ups' (Favale et al., 2020). Besides providing social contact between students, these also represent important channels for the sharing and dissemination of information and ideas, comparison of each other's work and forums for discussions and further consolidation of community and group binding. This informal mode of communication could promote peer interaction among student study groups or where students must collaborate with each other on group-based assessment tasks.

\section{Active and authentic learning}

In health professions education, finding authenticity and being proactive in the acquisition of knowledge and practical skills are recognised as essential components of students' professional development (Hamdy, 2015; Manninen, 2016). According to Pearse (2016), 'authentic learning is multi-disciplinary, skills-based learning in a real-life context, demonstrating to students that their learning is connected, relevant, and can have an impact upon the world around them, as well as their future selves' (p. 2). In sum, by ensuring that 'authenticity' is embedded in health professional students' academic and clinical learning experiences, this will encourage them to generate meaning out of their learning and make connections between previous learning and new learning, as well as between theory and practice. In this respect, the finding that senior students were more active and experienced greater authenticity during the period of online learning is a useful one. Despite the mid-range scores recorded by both sets of students on the active and authentic learning subscales, the analysis indicates that students in the later years of study were more accomplished in implementing their own learning strategies, seeking their own answers and solving their own problems. In contrast, first-year students are in the formative stages of developing their academic and cognitive capabilities, which include the independent learning skills required to fully engage in active learning. It is, therefore, important students develop the robust self-regulation skills that allow them to maintain levels of engagement and overcome the challenges of online learning environments (Lee et al., 2019).

First-year students may also lack the experiential resources in terms of real-life professional examples and clinical cases as points of reference that can be applied to what is being learned. This demonstrates the importance of online platforms that facilitate students to be active learners by providing meaningful learning opportunities, encouraging accountability for self-directed learning and controlling the pace of learning (Belarmino \& BahleLampe, 2019; Doyle \& Jacobs, 2013). For example, the use of video lectures in online curricula is reported to encourage active learning with students valuing the space 
of independent learning and options to pause, stop, go and rewind video content at their own pace (Scagnoli et al., 2019). These methods of online instruction also suit students who need extra time to learn and review content and those with busy schedules who enjoy the flexibility afforded by recorded lessons. Flexible modes of delivery and ease of access to content lead to higher levels of engagement among students, accommodate students' different learning styles and promote academic direction (Doyle \& Jacobs, 2013; Scagnoli et al., 2019).

Differences in the experiences and levels of engagement in online learning between first-year and senior students may also be explained by programme structure. For example, content in the first year of occupational therapy undergraduate programmes usually focuses on the acquisition of foundational knowledge units encompassing the structure and hierarchy of healthcare systems and psychology, desirable professional attributes, ethical behaviours, medico-legal issues, and anatomy and physiology content. This provides the ground for learning the practical and context-specific skills in the following years of study, during which students complete the required 1000 hours of practice education experience. Senior students, particularly those in their third and fourth years of study, will therefore have consolidated their experiences of working and applying their acquired knowledge in real-work settings, adding to their bank of experiences that can be drawn upon to inform and develop their professional toolbox. These students have at their disposal a wealth of case studies and factual information which can be related to class activities and assignments, adding authenticity to their theoretical and practical work.

This aligns with evidence from studies of older medical students during the pandemic which found that online platforms fostered active learning and positive experiences. Participants' levels of engagement could be gauged by educators during live online lectures to ensure consistent and engaging delivery of content; students were able to use chat boxes for ongoing discussions, and articles were able to be easily shared among the audience (Almarzooq et al., 2020). When programmes shift from teacher-led to more learner-controlled environments, the role of the educator becomes more facilitative, and it is necessary to provide the 'scaffolding' to maximise the potential for students to learn effectively (Geng et al., 2019). Scaffolding in this context refers to educators utilising a variety of instructional methods that assist students to gain greater insights and understanding about topics they are studying and in turn become more independent learners. With the rapid transition from faceto-face learning to the online delivery of programmes, and consideration given to how courses will be delivered in the future, it is, therefore, important to consider students' perceptions of and aspirations for online learning, as these directly influence how and where they learn (Ali, 2020; Mirzajani et al., 2016).

\section{Interactions with instructors}

Two notable outcomes from this study emerged in relation to the SELES interacting with instructors subscale. The descriptive statistics show that both first-year and senior year students recorded their lowest scores in this area with ANOVA further demonstrating a significant difference ( $p$ $=.026$ ) in self-reported scores between the two groups. These findings provide useful insights on students' experiences of their interactions and communications with academic staff during the period of online learning. The majority students, irrespective of group, struggled to communicate effectively with instructors when seeking clarification on lesson content or assignments, and they were reluctant to ask privately for extra help. The analysis of variance results indicated that senior year students perceived that they experienced more challenges related interacting and communicating with academic staff compared to their first-year counterparts.

For first-year students with no prior face-to-face interactions with new tutors and instructors, they may have felt little sense of relationship with academic staff, as they had not had time to form functioning studentinstructor bonds. This may be reflected in a lack of confidence in feeling able to approach lecturers and tutors with questions, seeking clarification about lesson content or requesting guidance on assignments during the period of online learning. This is contingent with previous research confirming that students in the early years of study undertaking online courses for extended periods are frequently associated with a sense of disconnection from educators (Henry, 2018; Rivera Munoz et al., 2020). Keengwe and Wisley (2012) emphasise the role of classroom settings in encouraging spontaneity and conversations and facilitating an environment where students and lecturers share the concepts of lived space, time and human interrelations; elements that can be missing from online interactions. Although well-structured synchronous online sessions provide opportunities for students to ask immediate questions of the instructor, when students do not have opportunities to engage and interact with educators in-person, the coconstruction of professional knowledge and building of communities of inquiry can be jeopardised (Khalili, 2020).

Almarzooq et al. (2020), in their review of online learning in graduate medical education during Covid-19, contend that to ensure the integration and welfare of students within academic communities, it is necessary to retain procedural and experiential in-person teaching 
as a complement to virtual simulation platforms. In the case of students with no prior experience in university settings, it is important that online learning programmes are balanced and carefully integrated with content to optimise students' engagement and promote meaningful dialogue with educators (Scagnoli et al., 2019). For example, student-instructor interactions can be enhanced by providing opportunities for feedback and input at selected points throughout the online lessons to ensure students are satisfied with the learning experience (Fish \& Wickersham, 2009). Within occupational therapy distance learning programmes, initiatives such as e-mentoring and personalised tutor and instructor feedback are reported to be effective development strategies that generate and sustain students' engagement in the online learning process and connection to a community of learners (Jacobs et al., 2013).

For students in their second year and beyond, it may be the case that having established a sense of rapport and effective student-instructor relationships derived from regular face-to-face interactions with academic staff in previous years of study, they felt disengaged and missed the immediate in-person group and personal contact with instructors. These findings link with the outcomes of other online learning studies that associate higher levels of engagement and successful learning with students' perception of teaching presence through continuous interactions and communications with instructors (Garrison et al., 2010; Joo et al., 2011; Jung $\&$ Lee, 2018). They also demonstrate the importance of online undergraduate programmes that encourage a sense of community and foster active interactions between participants; two factors that have been shown to enhance student satisfaction and retention rates (Lewis \& Abdul-Hamid, 2006). Therefore, the degree to which students interact with academic staff is a primary factor in improving student engagement in online learning. In relation to supporting student-instructor interactions, the use of videoconferencing tuition is described as a pedagogically sound technological tool for improving connectivity between students and instructors, while approaches that incorporate forum discussions, live sessions and direct messaging are reported to motivate and support students in building emotional ties with educators and programme content (Bates, 2015; Scagnoli et al., 2019; Stefanou et al., 2004).

\section{Implications and recommendations for education}

Establishing students' perceptions and experiences of online learning during the Covid-19 pandemic has several implications for educators and the design of teaching and learning experiences for occupational therapy students.
Identifying differences between senior and first-year students across measures of peer collaboration, active learning and interactions with instructors highlights the need for online programmes that deliver content to promote students' engagement with one another and their educators, and ensure authentic and meaningful learning experiences for participants. Initiatives such as interactive webinars, private and team chat messaging and video apps that encourage participants to communicate and disseminate information are essential tools in promoting active collaboration between learners and educators.

The online delivery of content over a full academic year across all year levels has afforded university educators a rare opportunity to review students' experiences of remote learning. While the current study identified some benefits of online learning such as opportunities for independent learning, it also revealed some of the significant difficulties students can experience when transitioning from the physical classroom to online settings, such as academic and social isolation, feelings of disengagement and a lack of motivation. In demonstrating the strengths and deficiencies of online learning programmes, educators will be encouraged to reflect on, assess and improve those elements that worked well and those that did not. It is not certain when students will resume oncampus education, or whether the future holds a return to in-person tuition, or a hybrid version where students attend some classes in-person and join others online. As such, it is essential that educators are cognisant of the academic, social and welfare considerations of students across all year levels and work towards the delivery of programmes that promote and maintain high degrees of engagement and interest.

\section{LIMITATIONS}

The limitations associated with this study include the convenience sampling approach used for recruitment. As the participants were recruited from two occupational therapy education programmes, generalisability of the findings is limited to similar contexts. The use of selfreport instruments in research also carries the potential for bias by participants reporting due to social desirability issues (Perinelli \& Gremigni, 2016). However, both instruments used have documented validity and reliability evidence reported about them. Another acknowledged limitation is the fact that a small percentage of students enrolled in the first year of the two occupational therapy programmes could have already completed one or more years of university-level study and then transferred into the occupational therapy programmes as first-year students. A final limitation is the low response rate of the two participants groups from the two courses to the online survey. 


\section{FURTHER RESEARCH}

Studies that replicate and add to the findings of the current study are recommended to extend assessment of the sustainability of online learning modalities. Longitudinal research that measures changes in students' levels of engagement during extended periods of online learning would provide additional insights into their adaptation to remote learning, to inform future delivery of content and facilitate the design of online learning programmes that are engaging and inclusive across all year levels. We also recommend research to determine whether improvements in occupational therapy students' independent learning capacities during periods of online learning have a significant and positive effect on assessment and performance. Further examination of the integration of telehealth as part of occupational therapy students' practice education experience is suggested. Finally, this study could be replicated with other university student groups enrolled in other health professional disciplines for comparison purposes using a mixed methods design.

\section{CONCLUSION}

The Covid-19 crisis has had a significant impact within health professional education in terms of curricula, time, budgets and staffing levels; however, it may yet act as a catalyst for educators to develop new resources and incorporate further blended learning techniques into current and future curricula. The challenge for educators in occupational therapy is to ensure that online delivery of classroom and fieldwork content does not compromise students' acquisition of core knowledge and skills required for their future careers. This study identified key differences between first-year and senior year students' experiences of and levels of engagement in online learning during the pandemic. The findings on measures of student collaboration, interactions with educators and active meaningful learning extend our early understanding of the matrix of factors that have impacted students during the enforced and extended period of online learning. The outcomes of the current study will therefore assist educators to develop contemporary and pedagogically sound approaches that facilitate flexible access to learning, in ways that provide students with meaningful experiences and engage them fully in active and genuine learning, whilst simultaneously safeguarding their social and personal well-being.

\section{FUNDING SOURCE}

The study was funded through a grant received from the Monash Education Academy Learning and Teaching 2018 Small Grants Scheme, Monash University, Victoria, Australia. The funding received covered the salary costs of a research assistant who helped with the data collection and data entry.

\section{AUTHORS' CONTRIBUTIONS}

Ted Brown designed the study and performed the statistical analyses. The seven other authors assisted with the data collection, interpretation of the data findings and drafting of the manuscript. All authors approved the final submitted manuscript.

\section{DECLARATION OF COMPETING INTERESTS}

There are no conflicts of interest related to this article.

\section{References}

Ali, W. (2020). Online and remote learning in higher education institutes: A necessity in light of COVID-19 pandemic. Higher Education Studies, 10(3), 16-25. https://doi.org/10.5539/hes.v10n3p16

Allen, I. E., \& Seaman, J. (2013). Changing course: Ten years of tracking online education in the United States. Babson Survey Research Group and Quahog Research Group.

Almarzooq, Z. I., Lopes, M., \& Kochar, A. (2020). Virtual learning during the COVID-19 pandemic: A disruptive technology in graduate medical education. Journal of the American College of Cardiology, 75(20), 2635-2638. https://doi.org/10.1038/s41433020-1080-0

Aristovnik, A., Keržic, D., Ravšelj, D., Tomaževic, N., \& Umek, L. (2020). Impacts of the COVID-19 pandemic on life of higher education students: A global perspective. Sustainability, 12, 8438. https://doi.org/10.3390/su12208438

Bates, T. W. (2015). Teaching in a digital age. Tony Bates Associates Ltd.
Belarmino, J., \& Bahle-Lampe, A. (2019). A preliminary historical report on embracing online education in occupational therapy. The Open Journal of Occupational Therapy, 7(3), 1-10. https://doi. org/10.15453/2168-6408.1554

Bezerra, I. M. P. (2020). State of the art of nursing education and the challenges to use remote technologies in the time of coronavirus pandemic. Journal of Human Growth and Development, 30(1), 141-147. http://doi.org/10.7322/jhgd.v30.10087

Burki, T. K. (2020). COVID-19: Consequences for higher education. The Lancet Oncology, 21(6), 758. https://doi.org/10.1016/S14702045(20)30287-4

Carini, R. M., Kuh, G. D., \& Klein, S. P. (2006). Student engagement and student learning: Testing the linkages. Research in Higher Education, 47(1), 1-32. https://doi.org/10.1007/s11162-005$8150-9$

Chen, P. S. D., Lambert, A. D., \& Guidry, K. R. (2010). Engaging online learners: The impact of Web-based learning technology on 
college student engagement. Computers \& Education, 54(4), 12221232. https://doi.org/10.1016/j.compedu.2009.11.008

Chernick, M. (2007). Bootstrap methods: A guide for practitioners and researchers. Wiley.

Coto, J., Restrepo, A., Cejas, I., \& Prentiss, S. (2020). The impact of COVID-19 on allied health professions. PloS One, 15(10), e0241328. https://doi.org/10.1371/journal.pone.0241328

Cuesta Medina, L. (2018). Blended learning: Deficits and prospects in higher education. Australasian Journal of Education Technology, 34(1), 42-56. https://doi.org/10.14742/ajet.3100

Doyle, N. W., \& Jacobs, K. (2013). Accommodating student learning styles and preferences in an online occupational therapy course. Work: A Journal of Prevention, Assessment \& Rehabilitation, 44(3), 247-253. https://doi.org.10.3233/WOR-121501

Favale, T., Soro, F., Trevisan, M., Drago, I., \& Mellia, M. (2020). Campus traffic and e-learning during COVID-19 pandemic. Computer Networks, 107290. https://doi.org/10.1016/j. comnet.2020.107290

Fish, W. W., \& Wickersham, L. E. (2009). Best practices for online instructors: Reminders. The Quarterly Review of Distance Education, 10, 279-284. https://www.learntechlib.org/p/106758/

Garrison, D. R., Anderson, T., \& Archer, W. (2010). The first decade of the community of inquiry framework: A retrospective. Internet and Higher Education, 13(1-2), 5-9. https://doi.org/10.1016/j. iheduc.2009.10.003

Geng, S., Law, K., \& Niu, B. (2019). Investigating self-directed learning and technology readiness in blending learning environment. International Journal of Educational Technology in Higher Education, 16, Article 17. https://doi.org/10.1186/s41239-0190147-0

Gustafsson, L. (2020). Occupational therapy has gone online: What will remain beyond COVID-19? Australian Occupational Therapy Journal, 67, 197-198. https://doi.org/10.1111/1440-1630.12672

Hamdy, H. (2015). Authentic learning in health professions education: Problem-based learning, team-based learning, task-based learning, case-based learning and the blend. In K. A. B. Abdulrahman, S. Mennin, R. M. Harden \& C. Kennedy (eds.). Routledge International Handbook of Medical Education (pp. 128-143). Routledge Handbooks Online. http://dx.doi.org/10.4324/9780203066201. ch10

Henry, M. (2018). The online student experience: An exploration of first-year university students' expectations, experiences and outcomes of online education [Doctoral dissertation, School of Arts and Humanities, Edith Cowan University, Western Australia, Australia]. https://ro.ecu.edu.au/theses/2059

IBM Corporation. (2017). IBM SPSS Statistics for Windows, Version 25.0. IBM Corp.

Jacobs, K., Doyle, N. W., \& Martin, R. (2013). Ensuring quality online education in occupational therapy. OT Practice, 21(October), 8-14. http://dx.doi.org/10.7138/otp.2013.1819f1

Jensen, L., \& Lally, K. (2018). Distance education in occupational therapy: Comparison of on-campus and hybrid student outcomes. American Journal of Occupational Therapy, 72(4), 7211510172p1. https://doi.org/10.5014/ajot.2018.72S1-PO3017
Joo, Y. J., Lim, K. Y., \& Kim, E. K. (2011). Online university students' satisfaction and persistence: Examining perceived level of presence, usefulness and ease of use as predictors in a structural model. Computers \& Education, 57(2), 1654-1664. https://doi. org/10.1016/j.compedu.2011.02.008

Jung, Y. J., \& Lee, J. M. (2018). Learning engagement and persistence in massive open online courses (MOOCS). Computers \& Education, 122, 9-22. https://doi.org/10.1016/j.compedu.2018.02.013

Keengwe, J., \& Wilsey, B. B. (2012). Online graduate students' perceptions of face-to-face classroom instruction. International Journal of Information and Communication Technology Education, 8(3), 45-54. https://doi.org/10.4018/jicte.2012070106

Keptner, K. M., \& McCarthy, K. (2020). Disruption of academic occupations during COVID-19: Impact on mental health and the role of occupational therapy in tertiary education. World Federation of Occupational Therapists Bulletin, 76(2), 78-81. https://doi.org/1 $0.1080 / 14473828.2020 .1822575$

Khalili, H. (2020). Online interprofessional education during and post the COVID-19 pandemic: A commentary. Journal of Interprofessional Care. 34(5), 687-690. https://doi.org/10.1080/13 561820.2020 .1792424

Lee, J., Song, H-D., \& Jeong Hong, A. (2019). Exploring factors, and indicators for measuring students' sustainable engagement in e-learning. Sustainability, 11, 985. https://doi.org/10.3390/ su11040985

Lewis, C. C., \& Abdul-Hamid, H. (2006). Implementing effective online teaching practices: Voices of exemplary faculty. Innovative Higher Education, 31(2), 83-98. https://doi.org/10.1007/s10755006-9010-z

Lewis, A. D., Huebner, E. S., Malone, P. S., \& Valois, R. F. (2011). Life satisfaction and student engagement in adolescents. Journal of Youth and Adolescence, 40(3), 249-262. https://doi.org.10.1007/ s10964-010-9517-6

Liu, Q., Peng, W., Zhang, F., Hu, R., Li, Y., \& Yan, W. (2016). The effectiveness of blended learning in health professions: Systematic review and meta-analysis. Journal of Medical Internet Research, 18(1), e2. https://doi.org/10.2196/jmir.4807

Longhurst, G. J, Stone, D. M., Dulohery, K., Scully, D., Campbell, T., \& Smith, C. F. (2020). Strength, Weakness, Opportunity, Threat (SWOT) analysis of the adaptations to anatomical education in the United Kingdom and Republic of Ireland in response to the Covid-19 pandemic. Anatomy Science Education, 13, 298-308. https://doi.org/10.1002/ase.1967

Manninen K. (2016). Experiencing authenticity - the core of student learning in clinical practice. Perspectives On Medical Education, 5(5), 308-311. https://doi.org/10.1007/s40037-0160294-0

Marks, R. (2020). Remote learning, face masks - Health sciences education adapts during COVID-19. The pandemic has also pushed students toward skills for the future. States News Service, 7 October, p. NA. https://link.gale.com/apps/doc/A637721047/AON $\mathrm{E} ? \mathrm{u}=\mathrm{monash} \& \mathrm{sid}=\mathrm{AONE} \& \mathrm{xid}=7 \mathrm{a} 28323 \mathrm{e}$

McCutcheon, K., Lohan, M., Traynor, M., \& Martin, D. (2015). A systematic review evaluating the impact of online or blended 
learning vs. face-to-face learning of clinical skills in undergraduate nurse education. Journal of Advanced Nursing, 71, 255-270. https://doi.org/10.1111/jan.12509

Means, B., Toyama, Y., Murphy, R., Bakia, M., \& Jones, K. (2009). Evaluation of evidence-based practices in online learning studies. U.S. Department of Education, Office of Planning, Evaluation, and Policy Development.

Mirzajani, H., Mahmud, R., Fauzi Mohd Ayub, A., \& Wong, S. L. (2016). Teachers' acceptance of ICT and its integration in the classroom. Quality Assurance in Education, 24(1), 26-40. https:// doi.org/10.1108/QAE-06-2014-0025

Mu, K., Coppard, B. M., Bracciano, A. G., \& Bradberry, J. C. (2014). Comparison of on-campus and hybrid student outcomes in occupational therapy doctoral education. American Journal of Occupational Therapy, 68(Suppl. 2), S51-S56. https://doi. org/10.5014/ajot.2014.685S02

Nicola, M., Alsafi, Z., Sohrabi, C., Kerwan, A., Al-Jabir, A., Iosifidis, C., Agha, M., \& Agha, R. (2020). The socio-economic implications of the coronavirus pandemic (COVID-19): A review. International Journal of Surgery (London, England), 78, 185-193. https://doi. org/10.1016/j.ijsu.2020.04.018

O'Sullivan, D., Rahamathulla, M., \& Pawar, M. (2020). The impact and implications of COVID-19: An Australian perspective. The International Journal of Community and Social Development, 2(2), 134-151. https://doi.org/10.1177/2516602620937922

Pearse, S. (2016). Authentic learning: What, why and how? E-Teaching, April(26), 1-3. http://www.acel.org.au/acel/ACEL_docs/ Publications/e-Teaching/2016/e-Teaching_2016_10.pdf

Perinelli, E., \& Gremigni, P. (2016). Use of social desirability scales in clinical psychology: A systematic review. Journal of Clinical Psychology, 72(6), 534-551. https://doi.org/10.1002/jclp.22284

Rabe, A., Sy, M., Cheung, W., \& Lucero-Prisno, D. (2020). COVID-19 and health professions education: A $360^{\circ}$ view of the impact of a global health emergency. MedEdPublish, 9(1), 148. https://doi. org/10.15694/mep.2020.000148.1

Regmi, K., \& Jones, L. (2020). A systematic review of the factors enablers and barriers - affecting e-learning in health sciences education. BMC Medical Education, 20, 91. https://doi. org/10.1186/s12909-020-02007-6

Rivera Munoz, C. A., Baik, C., \& Lodge, J. M. (2020). Teacher and student interactions in the first year of university. Journal of Further and Higher Education, 44(8), 1130-1142. https://doi.org/10.1080/ 0309877X.2019.1664731

Rogers, L. G., Mulholland, S., Derdall, M., \& Hollis V. (2011). From all perspectives: Opinions of students and teaching staff regarding occupational therapy distance education. British Journal of Occupational Therapy, 74(5), 241-248. https://doi.org/10.4276/03 0802211X13046730116579

Robinson, L., Brown, T., Fossey, E., Yu, M., Barclay, L., Chu, E., Peart, A., \& Callaway, L. (2020). Practice Education in Lockdown: Lessons Learned during the COVID-19 Global Pandemic. In D. Nestel, G. Reedy, L. McKenna, S. Gough (eds.), Clinical education for the health professions: Theory and practice. Springer Nature. https://doi.org/10.1007/978-981-13-6106-7
Robinson, C. C., \& Hullinger, H. (2008). New benchmarks in higher education: Student engagement in online learning. Journal of Education for Business, 84(2), 101-109. https://doi.org/10.3200/ JOEB.84.2.101-109

Scagnoli, N. I., Choo, J., \& Tian, J. (2019). Students' insights on the use of video lectures in online classes. British Journal of Education Technology, 50(1), 399-414. https://doi.org/10.1111/bjet.12572

Scott, J. (2020). Post Covid-19 in occupational therapy. British Journal of Occupational Therapy, 83(10), 607-608. https://doi. org/10.1177/0308022620957579

Stefanou, C. R., Perencevich, K. C., DiCintio, M., \& Turner, J.C. (2004). Supporting autonomy in the classroom: Ways teachers encourage student decision making and ownership. Educational Psychologist, 39(2), 97-110. https://doi.org/10.1207/s15326985ep3902_2

Thatcher, A., Zhang, M., Todoroski, H., Chau, A., Wang, J., \& Liang, G. (2020). Predicting the impact of COVID-19 on Australian universities. Journal of Risk and Financial Management, 13(9), 188. https://doi.org/10.3390/jrfm13090188

Walker, S. L. (2020). Distance Education Learning Environments Survey (DELES). Mind Garden, Inc.

Walker, S. L., \& Fraser, B. J. (2005). Development and validation of an instrument for assessing distance education learning environments in higher education: The Distance Education Learning Environments Survey (DELES). Learning Environments Research, 8(3), 289-308. https://doi.org/10.1007/s10984-005-1568-3

Zhou, N. (2020). Up to $50 \%$ of university students unhappy with online learning, regulator finds. The Guardian, 2 December. https:// www.theguardian.com/australia-news/2020/dec/02/up-to-50-ofuniversity-students-unhappy-with-online-learning-regulator-finds 